Proceeding

Oopen Access

A) CrossMark

\title{
Sensitization prevalence of children with allergic rhinitis to airborne and food allergens in Sakarya province of Turkey
}

\begin{abstract}
Introduction: Sensitization prevalence studies have been rarely reported in children with allergic rhinitis from different regions of Turkey and exact rate of some sensitizations in humid regions still are unknown. This is a part of extensive research including food and inhalant allergen sensitizations evaluated in the same study in a moist province of Turkey, Sakarya.
\end{abstract}

Aim: of this study was to explore what kind of allergens play a role in sensitizations of allergic rhinitis patients during childhood in Sakarya Province of Turkey.

Methods: 623 patients, $0-18$ years of age, who thought to have allergic rhinitis referred to only pediatric allergy outpatient clinic in Sakarya for an allergic evaluation between May 2013- June 2015. Multiple skin prick test system was used as a test apparatus to detect sensitization. For house dust mite testing Dermat. pter. / Dermat. farinae; animals: cat/dog; molds: Alternaria/Cladosporium; grasses: meadow fescue, nettle, mugwort, fathen, weed mix, cereal mix and grass mix; trees: cypress, ash, pine and olive; for foods: cow's milk, egg, peanut, hazelnut and fish extracts were utilized. Skin prick test evaluation criteria are as follows: Histamine response as positive control and equal positive response to histamine were accepted as $(3+)$ response, which is assumed to be significant sensitization.

Results: In overall; $289 / 623(46 \%)$ children showed $\geq(3+)$ response. According to 289 patients evaluation: there were $\geq(3+)$ sensitizations to pollen groups $(252 / 289$ : $87 \%)$; mites group $(51 \%)$; grasses $(66 \%)$; trees $(21 \%)$; molds $(8 \%)$; animals $(6 \%)$ and foods $(6 \%)$. In patients allergic to grass pollens: there were $\geq(3+)$ sensitizations to meadow $(14 \%)$, grassen $(11 \%)$, English plantain $(10 \%)$, cereal mix $(10 \%)$, nettle $(9 \%)$, weed mix $(4 \%)$, mugwort $(4 \%)$ and lambsquarters $(3.1 \%)$. In children allergic to tree pollens: there were $\geq(3+)$ sensitizations to olive $(8 \%)$, pine $(6 \%)$, cypress $(4 \%)$ and ash $(3 \%)$.

Conclusion: As expected, there were significant allergies mostly detected to pollens and mites in allergic rhinitis patients in our province. Amazingly, low overall sensitization rate $(<\% 10$ to molds) is found in our patients whom referred to us from humid Sakarya province.
Volume 3 Issue 2 - 2016

Öner Özdemir, Elmas B,Aydin E

Department of Pediatrics, Research and Training Hospital of Sakarya University, Turkey

Correspondence: Öner Özdemir, Division of Allergy and Immunology, Department of Pediatrics, Research and Training Hospital of Sakarya University, Faculty of Medicine, Sakarya University, Adnan Menderes Cad, Sağlık Sok No: 195, Adapazari, Sakarya, Turkey, Tel 90-264-444-54-00, Fax 90-264-275-91-92, Email ozdemir_oner@hotmail.com

Received: February 03, 2016 | Published: February 18, 2016

\section{Acknowledgments}

None.

\section{Conflicts of interest}

Authors declare that there is no conflict of interest. 